\section{Avaliação de impacto de ações de combate ao Aedes aegyptina cidade de Salvador, Bahia}

\section{Impact of action against Aedes aegypti in the city of Salvador, Bahia}

\author{
Maria da Glória Teixeira \\ Instituto de Saúde Coletiva \\ Universidade Federal da Bahia \\ Rua Padre Feijó, 29. $4^{\circ}$ andar do Hospital Pediátrico \\ 40110-170, Canela. Salvador - BA, Brasil \\ magloria@ufba.br \\ Maurício Lima Barreto \\ Instituto de Saúde Coletiva \\ Universidade Federal da Bahia \\ Maria da Conceição N. Costa \\ Instituto de Saúde Coletiva \\ Universidade Federal da Bahia \\ Leila Denise Alves Ferreira \\ Instituto de Matemática \\ Universidade Federal da Bahia \\ Pedro Fernando da Costa Vasconcelos \\ Instituto Evandro Chagas \\ Fundação Nacional de Saúde
}

\section{Auxílio financeiro}

Centro Nacional de Epidemiologia/Fundação Nacional de Saúde/ Ministério da Saúde. Convênios: 345/97; 2262/98.

\section{Resumo}

No atual estágio do conhecimento científico, a única medida de controle disponível para as infecções causadas pelo vírus da dengue é a eliminação do seu principal vetor urbano, o Aedes aegypti. O Brasil há muitas décadas desenvolve programas de combate a este mosquito; entretanto, observa-se desde o início dos anos oitenta uma expansão geográfica da infestação do seu território e circulação progressiva e intensa deste vírus, com registro de grandes epidemias e de transmissão endêmica em diferentes centros urbanos. Esta situação epidemiológica evidencia a existência de dificuldades para o controle destas infecções, razão pela qual o Ministério da Saúde solicitou uma avaliação da efetividade das ações que vinham sendo implementadas na cidade de Salvador pelo atual programa de combate vetorial, sendo o objetivo deste artigo apresentar os resultados deste estudo. Foi utilizado um desenho prospectivo, procedendo-se a inquéritos sorológicos de uma população amostral de indivíduos residentes em 30 distintos espaços da cidade - "áreas sentinelas". Os resultados revelaram elevadas soroprevalência $(67,7 \%)$ e soroincidência $(70,6 \%)$ para os sorotipos circulantes (DEN-1 e DEN-2), com grande variabilidade nos valores entre as 30 áreas estudadas. Verificou-se que a efetividade das medidas de combate vetorial é muito reduzida e, embora tenha sido encontrada uma Fração Prevenível de 29,7 \%, mesmo em áreas sentinelas com Índices de Infestação Predial $\leq 3 \%$, a incidência de infecções nestas áreas era ainda muito elevada $(55,4 \%)$. Os autores apontam para a necessidade de revisão das estratégias técnicas e operacionais do referido programa com vistas ao alcance de índices de infestação incompatíveis com a circulação do vírus da dengue.

Palavras-chave: Dengue. Epidemiologia. Aedes aegypti. Efetividade do controle. 


\section{Abstract}

According to the current scientific knowledge, the only available means of controlling infections caused by the dengue virus is the elimination of its principal urban vector, the Aedes aegypti mosquito. Brazil has been implementing programs to fight the mosquito for decades; however, since the beginning of the 1980's the geographic range of infestation has been expanding steadily, resulting in increased circulation of the virus, large epidemics, and increased endemic transmission in different urban areas. The current epidemiological situation confirms the difficulties of preventing infection, and has led the Ministry of Health to request an evaluation of the effectiveness of the dengue control actions that have been implemented in the city of Salvador. In this article, we present the results of this evaluation. Using a prospective design, serologic inquiries were made in a sample population of residents of 30 urban "sentinel areas." The results revealed high overall seroprevalence $(67.7 \%)$ and seroincidence $(70.6 \%)$ for the circulating serotypes (DEN-1 and DEN-2), with large variations among the 30 areas studied. The effectiveness of control measures appears to be low, and although a preventable fraction of $29.7 \%$ was found (even in sentinel areas with Infestation Rates $\leq 3 \%$ ), [Indices existe, mas rates é mais usado] the incidence of infections in these areas was still very high (55.4\%). We believe it is necessary to revise the technical and operational strategies of the infection control program in order to attain infestation levels that are low enough to interrupt the circulation of the dengue virus.

Keywords: Dengue. Epidemiology. Aedes aegypti. Control effectiveness.

\section{Introdução}

O controle das infecções pelo vírus da dengue vem tendo insucessos em quase todo o mundo em função da não disponibilidade de vacinas para utilização em populações humanas ${ }^{1}$ e da inexistência de drogas antivirais capazes de influenciar na redução da viremia.

Assim, as intervenções estão estritamente direcionadas para a eliminação do principal vetor desta enfermidade, o Aedes aegypt $\mathrm{I}^{2,3}$, mediante execução de três linhas de ações, quais sejam: saneamento do meio ambiente e atividades de educação que visam a redução dos criadouros potencias deste mosquito, e o seu combate direto por meio de agentes químicos, físicos e biológi$\cos ^{2,4}$.

Nas áreas infestadas pelo Aedes aegypti, principalmente nas grandes metrópoles, estes programas demandam atividades intensas e contínuas durante todos os dias do ano, com visitas casa a casa e vultuosos dispêndios de recursos. Em geral, quando estas ações são desenvolvidas de acordo com as normas técnicas preconizadas, obtém-se expressiva redução da população de mosquitos, mensurada mediante redução dos índices de infestação (Índice Predial/IP, Índice de Breteau/IB e outros). Entretanto, tem-se observado que nem sempre esta redução é acompanhada de impacto sobre as infecções do vírus da dengue ${ }^{1}$.

De acordo com a meta de cada programa, que pode ser controle ou erradicação do vetor, variam a extensão geográfica das ações, a duração e a freqüência dos ciclos de trabalhos; entretanto, as bases dos procedimentos técnicos operacionais são as mesmas $^{4}$. Ambas as estratégias enfrentam dificuldades para sustentar níveis de infestação incompatíveis com a transmissão do vírus da dengue ${ }^{1}$, principalmente em regiões onde as condições climáticas são favoráveis à sua proliferação².

Há muitas décadas o Brasil vem desenvolvendo ações de combate ao Aedes aegypti, tendo inclusive alcançado sua erradicação em 1958, ficando livre deste vetor durante 
alguns anos. Após a sua reintrodução em 1976 não mais conseguiu eliminá-lo e, dez anos após, a estratégia de erradicação foi substituída pelo controle ${ }^{5}$. Entretanto, como a situação epidemiológica da dengue no país foi se agravando ${ }^{5}$, em 1995 uma equipe de cientistas e técnicos convocados pelo Conselho Nacional de Saúde examinou a questão e propôs o retorno à estratégia anterior, apresentando a metodologia e os procedimentos (Plano Diretor e Plano Piloto-PEA) que deveriam ser adotados para se alcançar tal fim ${ }^{6}$. Esta proposta não foi implantada, e em seu lugar implementou-se outra (PEAa, 1997 ${ }^{7}$, que embora não atendesse o modelo anterior continuou sendo denominada de Plano de Erradicação do Aedes aegypti. Maiores aportes de recursos foram então destinados ao programa; entretanto, não se observou na evolução temporal da doença indícios de que as ações implementadas estivessem contribuindo para a redução da transmissão do vírus da dengue ${ }^{8,9}$.

Em vista deste comportamento, o Ministério da Saúde solicitou uma avaliação da efetividade das ações que vinham sendo implementadas por este programa na cidade de Salvador. Assim, este artigo tem como objetivo apresentar os resultados deste estudo.

\section{Metodologia}

Trata-se de uma avaliação, baseada em um estudo prospectivo, realizada em Salvador - Bahia, cidade do Nordeste do Brasil que, em 1998, possuía cerca de 2,3 milhões de habitantes, onde foram delimitadas 30 áreas sentinelas na sua malha urbana, selecionadas com base na cobertura de saneamento e nível de renda. Estes indicadores foram considerados um proxy das condições de vida das populações residentes ${ }^{10}$.

Admitindo-se uma soroprevalência de $50 \%$, que é a média observada em inquéritos anteriores realizados em capitais brasileiras $^{11,12}$, assumindo-se uma precisão $\leq 3 \% \mathrm{e}$ nível de confiança de 95\%, o tamanho da amostra foi estimado em 1503 indivíduos, que acrescentada de $30 \%$ para compensar as possíveis perdas resultou em 2.149 indivíduos. Utilizando-se a base de dados de um censo demográfico realizado no ano de 1997 nas 30 áreas sentinelas, quando foram enumerados 68.749 indivíduos, foi feito o sorteio aleatório dos participantes sem reposição, e a seguir agrupados nas áreas, considerando o endereço residencial ${ }^{13}$.

Após o protocolo de investigação ter sido submetido e aprovado pela Comissão de Ética em Pesquisa Científica do Centro de Pesquisa Gonçalo Moniz/FIOCRUZ-BA, foi aplicado, entre maio e julho de 1998, um questionário estruturado que incluía nome, endereço, sexo, idade, nível educacional, e história de vacinação contra febre amarela. Logo após a entrevista eram prestados esclarecimentos quanto à natureza do estudo e solicitada a assinatura do Consentimento Informado, colhendo-se em seguida a primeira amostra de sangue. Os três indivíduos que informaram terem sido vacinados contra febre amarela foram excluídos, visando evitar falsos testes sorológicos positivos devido a reações cruzadas. Uma segunda amostra de sangue foi colhida um ano depois, daqueles indivíduos que apresentaram reações negativas ou positivas para apenas um sorotipo do vírus da dengue no primeiro inquérito sorológico. O sangue foi coletado mediante punção venosa, utilizando-se tubos a vácuo de $10 \mathrm{ml}$ e agulhas descartáveis esterilizadas, sendo o soro separado por centrifugação e estocado a $-20^{\circ} \mathrm{C}$. Estas amostras foram enviadas para o Laboratório de Arbovírus do Instituto Evandro Chagas, onde era processada a reação de Inibição de Hemaglutinação / $/ \mathrm{IH}^{14}$, modificada ${ }^{15}$, utilizando-se antígenos dos quatro sorotipos dos vírus da dengue e de mais quatro flavivírus: Febre Amarela (FA), Rocio (ROC), Ilhéus (ILH) e Encefalite Saint Louis (SLE), embora estes não circulassem em Salvador. Como a interpretação das respostas sorológicas aos flavivírus são controversas e diferem entre a primeira (primária) e subseqüente (secundária) infecção com outros flavivírus ou sorotipos, e é freqüentemente observada reação cruzada, o critério utilizado foi o adotado pela Organização Mundial 
de Saúde ${ }^{16}$, ou seja, títulos de IH iguais ou maiores que 1:20 exclusivamente para um sorotipo específico da dengue, ou títulos quatro vezes mais altos para um do que para outro sorotipo (DEN-1 ou DEN-2) que circulava em Salvador, foram considerados positivos e específico para aquele sorotipo (resposta primária). Títulos indicativos de resposta secundária, também definidos pelo critério da OMS, foram em seguida confirmados pela reação de IgG ELISA ${ }^{17}$ e considerados positivos para ambos os sorotipos, significando que ocorreram infecções por DEN 1 e DEN 2.

Para cada área sentinela calculou-se as soroprevalências e soroincidências para infecções pelo vírus da dengue, bruta e padronizada por idade, pelo método indireto ${ }^{18}$, utilizando-se como população de referência a composição total da amostra do estudo. Como o intervalo entre os dois inquéritos foi de um ano, a soroincidência foi expressa em taxa anual por cento. Foram estimados a Razão de Prevalência (RP) e o Risco Relativo (RR) das infecções pelo vírus da dengue e intervalo de confiança a 95\%. Análise exploratória foi realizada para descrever as características da população do estudo e verificar a existência de associação entre variáveis (a densidade populacional média foi obtida do censo de 1996 realizado pelo FBIGE), utilizando-se o coeficiente de correlação de Pearson.

Foram estimadas a média e mediana dos Índices de Infestação do Aedes aegypti (IP) dos bairros sob intervenção (tratamento químico dos focos com larvas do vetor e informação oral aos residentes de cada domicílio das formas de evitar criadouros do mosquito) do PEAa ${ }^{7}$ a partir de dados levantados dos relatórios trimestrais, do período deste estudo (1998 e 1999), do Centro de Controle de Zoonozes da Secretaria Municipal de Saúde de Salvador ${ }^{19,20}$.

Além disso, em abril de 1999 foram inspecionados todos os domicílios das 30 áreas sentinelas quando se registrava as anotações das visitas dos agentes de saúde do PEAa de Salvador e verificava a existência de focos do Aedes aegypti.
A unidade de análise foi o agregado espaço populacional representado pelas áreas sentinelas. Considerou-se positivo todo prédio com um ou mais criadouro com larvas ou ovos deste mosquito, estimando-se por área sentinela o Índice Predial (IP) como a percentagem de prédios positivos ${ }^{21}$. Mediante análise de Covariância ${ }^{22}$, as incidências de infecções para cada faixa de IP $(\leq 3 \%$; $3.1 \%$ a $5 \%$; $5.1 \%$ a $10 \%$; e $>10 \%$ ) foram calculadas, ajustando-se pela idade e média de soroprevalência. A Fração Prevenível (FP) foi estimada considerando-se como "não expostos" os indivíduos que residiam nas áreas com IP $\leq$ que 3 por cento.

Os dados foram digitados no Epi-Info 6.0 e analisados no SAS e STATA.

\section{Resultados}

Participaram do estudo 1515 indivíduos dos 2.149 sorteados (70\%); entretanto, as perdas estavam distribuídas aletoriamente, não havendo diferenças demográficas entre os indivíduos estudados e os perdidos. Quase $58 \%$ dos indivíduos incluídos no estudo eram do sexo feminino e a distribuição etária mostrou que $5,1 \%$ tinham menos de cinco anos, 20,9\% estavam entre 5-14 anos, e 74\% acima de 15 anos. A maioria (68,3\%) dos indivíduos com idade acima de 15 anos tinha menos de 8 anos de escolaridade, cerca de $25 \%$ da população do estudo informou que a renda familiar era menor que dois salários mínimos da época (US $\$ 80 /$ mês), e para $50 \%$ esta renda era entre 2 e 5 salários mínimos.

No inquérito inicial, a soroprevalência média foi de $68,7 \%$ (Tabela 1) variando de $16.2 \%$ a $97,6 \%$ entre as 30 áreas do estudo, sendo mais baixa entre os indivíduos com menos de 15 anos de idade (39.0\%) e mais elevada $(76,4 \%)$ na faixa de 30 a 39 anos.

No segundo inquérito participaram 595 indivíduos dos 860 que haviam apresentado sorologia negativa ou positiva para apenas um dos sorotipos do vírus do dengue no primeiro exame, o que representou $30,8 \%$ de perdas, sendo a maioria por mudança de endereço. Por se tratar de um estudo de agregado espaço-populacional, não havia 
indicação de localizar estas perdas. Entretanto, a estrutura social e demográfica da amostra manteve-se semelhante à do primeiro inquérito. A taxa de soroincidência média de infecções para o vírus do dengue foi de $70.6 \%$, variando de $50 \%$ a $90 \%$ entre as áreas do estudo, sendo mais elevada onde a soroprevalência inicial foi mais baixa. Observou-se também que a soroincidência foi maior nos indivíduos com sorologia prévia positiva para um dos sorotipos do vírus da dengue $(83,0 \%)$ do que para aqueles que haviam sido negativos no primeiro inquérito $(60,8 \%)$ (Tabela 2).

Todas as 30 áreas deste estudo estavam sendo objeto de intervenção do PEA de Salvador, e de acordo com os dados dos relatórios do Centro de Controle de Zoonozes (CCZ) os IP dos diferentes bairros da cidade variaram de $0,3 \%$ a $24,7 \%$, com média de $6,5 \%$ e mediana de $4,9 \%$. O Índice Predial de Aedes aegypti (IP) encontrado no levantamento realizado nestas 30 áreas variou de $0.27 \%$ a $25.6 \%$, sendo a média de $7,4 \%$ e mediana de $5,2 \%$. Tanto nos registros do CCZ como no levantamento realizado em apenas $20 \%$ dos bairros e áreas sentinelas, respectivamente, este indicador estava abaixo de 3\%. Encontrou-se correlação positiva, porém não significante, entre o IP das áreas sentinelas e a soroincidência $(\mathrm{r}=+0,17 ; \mathrm{p}=$ 0,36 ). Ao se agrupar estas 30 áreas de acordo com seus níveis de IP observou-se que mesmo nas áreas onde este indicador era baixo $(\leq 3 \%)$ a soroincidência ajustada pela idade e soroprevalência prévia ainda era muito elevada (54,6\%), existindo diferença estatisticamente significante entre o primeiro e o segundo grupo de IP ( $\mathrm{RR}=1,38$; 95\% CI 1,07$1,77)$, mas o teste de Qui quadrado de tendência não foi estatisticamente significante $\left(\chi_{\text {for trend }}^{2}=0,14 ; p<0,71\right)$. A soroincidência, embora ainda elevada, foi significantemente menor nas áreas com IP $\leq 3 \%$, considerado deste modo como o nível abaixo do qual a taxa de transmissão começaria a decrescer (Gráfico). Assim, este limiar foi tomado como referência para estimativa da Fração Prevenível imputada à redução do IP cujo valor foi de $29,7 \%$ para Salvador.

Tabela 1 - Soroprevalência para dengue na amostra de indivíduos residentes em 30 áreas sentinelas. Salvador - Bahia, 1998.

Table 1 - Dengue seroprevalence in the sample of residents of 30 sentinel areas. Salvador-Bahia, 1998

\begin{tabular}{lcc}
\hline Sorologia & No $^{\circ}$ & Prevalência (\%) \\
\hline Positiva para um sorotipo & 386 & 25,5 \\
Positiva para dois sorotipos & 655 & 43,2 \\
Negativa & 474 & 31,3 \\
Total & 1.515 & 100,0 \\
\hline
\end{tabular}

Tabela 2 - Soroincidência de infecções pelo vírus da Dengue em indivíduos residentes em 30 áreas sentinelas de acordo com a situação imunológica anterior. Salvador-Bahia, 1999. Table 2 - Sero-incidence of Dengue virus infections in residents of 30 sentinel areas, according to previous immunologic status. Salvador-Bahia, 1999.

\begin{tabular}{lccccc}
\hline & & \multicolumn{4}{c}{ Incidência de Infecção } \\
\cline { 3 - 6 } Situação imunológica anterior & $N$ & & 1 Sorotipo & \multicolumn{2}{c}{ 2 Sorotipos } \\
\cline { 3 - 6 } & & No & $\%$ & No & $\%$ \\
\hline Negativos & 331 & 77 & 23,3 & 124 & 37,5 \\
Positivos para 1 sorotipo & 264 & 219 & 83,0 & - & - \\
Total & 595 & 296 & 49,8 & 124 & 20,8 \\
\hline
\end{tabular}




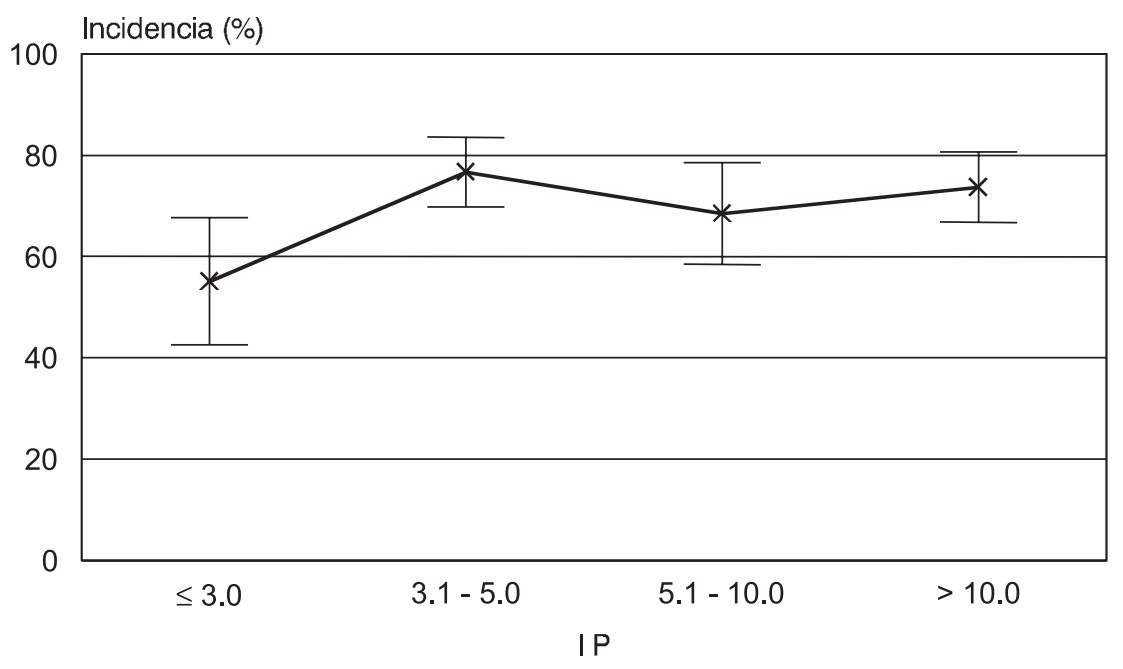

Gráfico - Incidência de infecção pelos sorotipos 1 e 2 do vírus do dengue, ajustada pela soroprevalência e idade média de residentes em 30 áreas sentinelas, por grupos de Índices de Infestação Predial (IP) de Aedes aegypti e respectivos intervalos de confiança. SalvadorBahia, 1999.

Chart - Incidence of infection by dengue virus serotypes 1 and 2, adjusted by seroprevalence and average age of residents for 30 sentinel areas, by Aedes aegypti Building Infestation Rates (IP) groups and respective confidence intervals. Salvador-Bahia, 1999

\section{Discussão}

A elevada incidência de infecção pelo vírus do dengue entre os indivíduos susceptíveis que participaram do segundo inquérito por si só já é sugestiva do reduzido impacto que vem sendo obtido pelo programa de combate ao Aedes aegypti, muito embora estas ações já estivessem sendo implementadas há mais de 30 meses em Salvador. O encontro de valores destas taxas superiores a $50 \%$ em todos os níveis de IP considerados no estudo revela que a transmissão viral é muito intensa. Por outro lado, a maior soroincidência subsequente nos indivíduos que já apresentavam sorologia positiva para um sorotipo no primeiro inquérito evidencia que estes permaneceram mais expostos ao vetor, apesar das ações de combate que vinham sendo desenvolvidas.

Supunha-se que as atividades de combate ao vetor instituídas no município desde janeiro de 1997, e que a imunidade de grupo da população, ainda que parcial, revelada pelas soroprevalências encontradas no inquérito de 1998, contribuíssem para a redu- ção da circulação viral entre os susceptíveis, o que não foi constatado. Dois anos e meio após a implantação das atividades de combate vetorial na cidade, o valor médio de IP encontrado no presente estudo foi muito semelhante ao dos registros oficiais. Além disso, existe a probabilidade de que este indicador poderia estar mais elevado nos bairros onde estas atividades não vinham sendo desenvolvidas, conforme registrado no relatório do próprio Centro de Controle de Zoonozes da cidade ${ }^{20}$.

Muito embora tenha se observado entre 1997 e 1999 uma redução de 50\% nas médias de IP nos bairros de Salvador em que foram realizados levantamentos ${ }^{19,20}$, isto indica que houve uma certa eficiência do programa, mas que não foi suficiente para produzir um impacto significativo na transmissão, visto a acentuada intensidade de transmissão viral encontrada.

Nas áreas em que ocorreram reduções mais importantes de densidade da população de vetores alcançando IP<3\%, o impacto sobre a redução da soroincidência do dengue foi de apenas $30 \%$. Porém, ainda assim, 
naquelas áreas em que ocorreu redução, o coeficiente de incidência foi muito elevado (>50\%), podendo-se considerar este achado uma forte evidência da limitada efetividade das ações deste combate vetorial. Por outro lado, vale salientar que em apenas 6 (20\%) das 30 áreas o IP atingiu este valor.

Estes achados não surpreendem e estão de acordo com o modelo teórico de transmissão de dengue, desenvolvido por Newton \& Reiter $^{23}$, baseado na experiência de Singapura, que mostrou que a simples redução da população de vetores que não alcance índices muito próximos a zero não é capaz de alterar a força de transmissão do vírus do dengue. A intensa circulação viral detectada em Salvador, tanto do sorotipo DEN-1 como do sorotipo DEN-2, sugere que, no decorrer do tempo, quase toda a população da cidade será infectada, caso sejam mantidas as atuais condições ambientais que são bastante favoráveis à circulação do agente.

O baixo impacto deste programa de combate vetorial possivelmente resulta da estratégia inadequada que vem sendo implementada em Salvador, e que também vem sendo adotada em muitas outras cidades do país. Não são desenvolvidas ações de saneamento do meio ambiente capazes de reduzir significativamente a quantidade de criadouros potenciais do Aedes aegypti; são insuficientes as atividades de educação/informação para que a população participe de modo contínuo na destruição e ou proteção dos depósitos que podem se transformar em ambiente propício à proliferação deste mosquito; e no combate químico, que além de tudo sofre interrupções freqüentes, os ciclos de tratamento são feitos a intervalos além dos 60 dias preconizados.

É fato que esses problemas são decorrentes de repasses de recursos intermitentes e insuficientes para a execução dos pro- cedimentos técnicos necessários para reduzir a população de um mosquito que apresenta enorme capacidade de adaptação aos ambientes urbanos ${ }^{2}$. Além disso, o desenvolvimento de resistência aos produtos químicos utilizados indica a necessidade de monitoramento e rodízio destas substânci$\mathrm{as}^{4}$, e as dificuldades de acesso aos domicílios para tratamento dos focos deste vetor impõem o desenvolvimento de estratégias especiais e contínuas para adesão da população às atividades do programa. Estes procedimentos também não vinham sendo desenvolvidos sistematicamente em Salvador.

Para que se alcancem índices de infestação incompatíveis com a transmissão viral, o combate a este mosquito exige continuidade e universalidade das ações em cada território, conforme preconizado no Plano Diretor de Erradicação do Aedes aegypti do Brasil. Entretanto, o programa ora implementado no Brasil vem desconsiderando a necessidade de um mínimo de regionalização das áreas sob intervenção, mesmo quando se trata de municípios conurbados, como a região metropolitana de Salvador, onde apenas alguns deles foram beneficiados. Deste modo, níveis de infestação por este vetor, compatíveis com a eliminação da circulação viral, dificilmente são alcançados, o que resulta em baixa efetividade das ações implementadas como demonstrado neste estudo.

Entretanto, o dispêndio de recursos para estas atividades que produzem tão baixo impacto é elevado quando se considera o montante destinado à área de Saúde Pública no Brasil, o que aponta para a urgente necessidade de revisão da estratégia que vem sendo adotada, com a pronta incorporação dos princípios e técnicas de combate ao Aedes aegypti já bastante estabelecidos na literatura científica e capazes de imprimir maior efetividade a este programa. 
1. Guzman MG. Avances para la obtención de una vacina contra el dengue. Acta Cient Venez 1988; 49(1): 38-45.

2. Reiter P, Gubler DJ. Surveillance and control of urban dengue vectors. In: Gubler DJ, Kuno G Editors. Dengue and dengue hemorragic fever. New York: $\mathrm{CAB}$ International; 1997, p. 45-60.

3. Kuno G. Review of the factors modulating dengue transmission. Epidemiol Rev 1995; 17(2).

4. Organização Panamericana de Saúde-OPS. Dengue y dengue hemorrágico en las Americas: guias para su prevención y control. Washington DC; 1995. OPS. (Publicación Científica, 548).

5. Teixeira MG, Barreto ML. Porque devemos, de novo, erradicar o Aedes aegypti. Ciência \& Saúde Coletiva 1996; 1: 122-35.

6. Brasil. Ministério da Saúde. Fundação Nacional de Saúde. Plano Diretor de Erradicação do Aedes aegypti do Brasil (PEA). Brasília (DF); 1996.

7. Fundação Nacional de Saúde. Ministério da Saúde. Plano Diretor de Erradicação do Aedes aegypti do Brasil ajustado (PEAa). Brasília (DF); 1997.

8. Teixeira MG, Barreto LM, Guerra Z. Epidemiologia e medidas de prevenção do dengue. Informe Epidemiológico do SUS 1999; 8(4):5-33.

9. Teixeira MG, Costa MCN, Barreto ML, Barreto F. Epidemiologia do dengue em Salvador- Bahia, 19951999. Rev Soc Bra Med Trop mai-jun 2001; 34(3): 26974.

10. Teixeira MG, Barreto Ml, Costa MCN, Strina A, Martins Júnior D, Prado M (2002). Sentinel areas: Public Health surveillance strategy. Cad Saúde Pública 2000 (no prelo).

11. Vasconcelos PFC, Lima JWO, Travassos da Rosa PA et al. Epidemia de dengue em Fortaleza, Ceará: inquérito soro-epidemiológico aleatório. Rev Saúde Pública 1998; 32: 447-54.

12. Cunha RV da,Dias M, Nogueira RMR, Chagas N, Miagostovich MP, Schatzmayr HG. Secondary dengue infection in schoolchildren in a dengue endemic area in the state of Rio de Janeiro, Brazil. Rev Inst Med Trop São Paulo 1995; 37: 517-21.
13. Cochran WG, Sampling techniques. New York: Ed. Jonh Wiley \& Sons. 3a edição; 1977.

14. Clark DH, Casals J. Techniques for hemagglutination and hemagglutination-inhibition with arthropodborne viruses. Am J Trop Med Hyg 1958; 7: 561-77.

15. Shope RE. The use of a hemagglutination-inhibition test to follow antibody response after arthropod-borne virus infection in a community of a forest animals. Anais de microbiologia 1963 (Rio de Janeiro); 11(parte A):167-71.

16. World Health Organization. Dengue Hemorrhagic Fever: diagnosis, treatment, prevention and control. $2^{\text {nd }}$ edition, Geneva; 1997.

17. Chungue E, Marché R, Plichart J, Bovin JP \& Roux J. Comparison of immunoglobulin $\mathrm{G}$ enzyme-linked immunosorbent assay (IgG-ELISA) and hemagglutination inhibition (HI) test for the detection of dengue antibodies. Prevalence of dengue IgGELISA antibodies in Tahiti. Trans $\boldsymbol{R}$ Soc Trop Med Hyg 1989; 83: 708-11.

18. Rothman KJ. Modern epidemiology. Ed Little, Brown and Company, Boston - Toronto, 1986, p. 41-9.

19. Gomes AC. Medidas dos níveis de infestação urbana para Aedes (Stegomyia) aegypti e Aedes (Stegomyia) albopictus em programa de vigilância entomológica. Informe Epidemiológico do SUS jul-set 1998; VII(3).

20. Montgomery DC. Design and analysis of experiments. $3^{\text {a }}$ ed. New York: Wiley; 1991.

21. Secretaria Municipal de Saúde. Centro de Controle de Zoonozes, Plano de Erradicação do Aedes aegypti no Município de Salvador. Relatório do $3^{\circ}$ ciclo de 1999. Prefeitura Municipal de Salvador; 1999.

22. Secretaria Municipal de Saúde. Centro de Controle de Zoonozes, Plano de Erradicação do Aedes aegypti no Município de Salvador. Relatório parcial das ações do Plano de combate ao Aedes aegypti. Prefeitura Municipal de Salvador; 1998.

23. Newton EA, Reiter P. A model of the transmission of dengue fever with and evaluation of the impact of ultra-low volume (ULV) inseticide applications on dengue epidemics. Am J Trop Med Hyg 1992; 47: 709-20.

Recebido em 04/01/02; aprovado em 15/08/02 